DIGITALCOMMONS @WAYNESTATE —
Michigan Journal of Counseling:

Research, Theory and Practice

Volume 40 | Issue 2

Article 3

$12-1-2013$

\title{
Promoting Client Welfare and Preserving Autonomy: Ethical Treatment of Eating Disorders
}

Julia E. Smith

University of North Texas

Emily Michero

University of North Texas

Kerrie R. Fineran

Indiana University-Purdue University, Fort Wayne

Follow this and additional works at: https://digitalcommons.wayne.edu/mijoc

\section{Recommended Citation}

Smith, J. E., Michero, E., \& Fineran, K. R. (2013). Promoting Client Welfare and Preserving Autonomy: Ethical Treatment of Eating Disorders, Michigan Journal of Counseling, 40(2), 12-27. doi:10.22237/mijoc/1385856120

This Article is brought to you for free and open access by the Open Access Journals at DigitalCommons@WayneState. It has been accepted for inclusion in Michigan Journal of Counseling: Research, Theory and Practice by an authorized editor of DigitalCommons@WayneState. 


\section{Promoting Client Welfare and Preserving Autonomy: Ethical Treatment of Eating Disorders}

Julia E. Smith ${ }^{1}$, Emily Michero ${ }^{1}$, and Kerrie R. Fineran ${ }^{2}$

University of North Texas ${ }^{1}$ and Indiana University-Purdue University, Fort Wayne $^{2}$

\section{Abstract}

Counselors often experience an ethical dilemma when mandating treatment for clients with eating disorders. In this article, the authors will briefly discuss the characteristics of eating disorders, the impact of cognitive impairment on the decision to mandate treatment, and the ethical principles of autonomy, beneficence, and nonmalificence that counselors must consider when working with clients from this population. To address ethical concerns, the authors will apply Welfel's (2010) ethical decision-making model to a case involving a client with Anorexia Nervosa.

\section{Promoting Client Welfare and Preserving Autonomy: Ethical Treatment of Eating Disorders}

Eating disorders (EDs) are complex and often life threatening conditions. According to the Diagnostic and Statistical Manual of Mental Disorders, 5th Edition (DSM-5) (American Psychiatric Association, 2013), EDs are generally characterized by disturbances in eating behavior. EDs are classified into one of several specific categories: anorexia nervosa, bulimia nervosa, binge eating disorder, and feeding or eating disorder not elsewhere classified. Anorexia nervosa (AN) is characterized by restriction of food intake, refusal to maintain minimally appropriate body weight, intense and irrational fear of weight-gain, and distorted body image. Bulimia nervosa $(\mathrm{BN})$ is marked by the consumption of a

Julia E. Smith is a doctoral student in Counseling at the University of North Texas and is a Licensed Professional Counselor-Intern practicing in Fort Worth, Texas. Emily Michero is a doctoral candidate at the University of North Texas and is a Licensed Professional Counselor Supervisor practicing in Fort Worth, Texas. Kerrie R. Fineran is an assistant professor of Counselor Education at Indiana University-Purdue University, Fort Wayne. Her professional interests relate to counseling adolescents, substance and process addictions, and counselor training. 
large amount of food in a short period of time; individuals with bulimia often report feeling out of control during consumption and appear to possess a selfimage that is disproportionately influenced by body image. Binge eating disorder (BED) is defined as frequent episodes of eating significantly more food in a short period of time than the average person would eat under similar circumstances. Individuals with BED often experience feeling out of control and may eat too quickly, even when not hungry. Episodes may be accompanied by feelings of guilt or shame, thus individuals with BED may hide binge-eating behavior. BED is associated with marked distress and typically occurs at least once a week over at least three months. The category feeding and eating disorders not elsewhere classified includes eating disorders that do not meet the diagnostic criteria for AN, BN, or BED, including, atypical AN, sub-threshold BN, subthreshold BED, and purging disorder. The subtypes of EDs share commonalities such as fear of weight gain, body image dissatisfaction, and preoccupation with food.

EDs have a significant personal, familial, societal, and health impact. Individuals with eating disorders often develop medical complications. As reported by Stice, Marti, and Rohde (2013), the lifetime prevalence of AN in American women is approximately $0.8 \%$, for $\mathrm{BN}$, it is $2.6 \%$, for $\mathrm{BED}$ it is $3.0 \%$, and for FEDEC, it is $11.5 \%$. The total lifetime prevalence for all EDs is $13.1 \%$. College-age women are at a greater risk for eating disorders than the general population (Schoen et al., 2012). EDs have the highest mortality rate of any mental disorder and are more lethal for women aged 15-24 than any other condition (Sullivan, 2002). Crow et al. (2009) reported the approximate mortality rates for individuals with EDs as $4 \%$ for those with AN, $3.9 \%$ for those with BN, and $5.2 \%$ for those with other eating disorders, including BED. Additionally, individuals with EDs also have an elevated risk of suicide (Apter et al., 1995; Bulik, Sullivan \& Joyce, 1999; Pompili et al., 2004; Preti, Rocchi, Sisti, Camboni, \& Miotto, 2011), and co-morbid mental health disorders including various types of mood, anxiety, personality, and substance use disorders (American Psychological Association, 2009). Many individuals with eating disorders die of starvation related illnesses and, for individuals with $\mathrm{AN}$, the rate of suicide is up to fiftyseven times higher than that of the general population. The lifetime frequency of suicide attempts in individuals with $\mathrm{BN}$ has been estimated to be between 15\% and 40\% (Bulik et al., 1999; Corcos et al., 2002; Favaro \& Santonastaso, 1997; Preti et al., 2011) and in individuals with AN to be between $5 \%$ and 22.9\% (Favaro et al., 1997; Preti et al., 2011, Pryor et al., 1995). Sullivan (1995) noted that the second most common cause of death in AN sufferers was completed suicide, which accounted for $27 \%$ of fatalities.

Clearly, EDs are potentially lethal disorders that may require intensive intervention by counselors. In many cases, individuals with EDs have no inten- 
tion of changing their behavior and are often either unaware of or unwilling to accept the physical dangers of their conditions. The purpose of this article is to describe ways in which people with EDs may experience cognitive and decision -making impairments, to highlight the ethical dilemmas that may arise with clients who are unwilling to seek additional treatment, and to provide a case example demonstrating the application of Welfel's (2010) ethical decision-making model as a way to manage and balance ethical issues that may arise during counseling with eating disordered clients.

\section{Cognitive Impairment and Treatment Implications}

EDs are often accompanied by thought disturbances, which may lead individuals to actively resist change, be noncompliant with treatment, and value declining weight and health. Individuals with EDs often struggle with cognitive impairment and have difficulty with appropriate decision-making (Boeka \& Lokken, 2006; Brand, Frank-Sievert, Jacoby, Markowitsch, \& Tuschen-Caffier, 2007; Cavedini et al., 2004, 2006; Tchanturia et al., 2007). Assessing potential impairment is critically important to counselors working with individuals with EDs as it may impact the individual's motivation for change. Impaired decisionmaking can impact an individual's ability to make rational and independent decisions regarding food and health. As such, people with EDs often lack anxiety about the dangers of their harmful behaviors and the resulting life-threatening symptoms.

Clients, with AN may have impaired mental flexibility and experience difficulty shifting focus. This impaired mental flexibility may contribute to the obsessive focus anorexic clients often have on the avoidance of weight gain (Cavendini et al., 2004; Roberts, Tchanturia, Stahl, Southgate, \& Treasure, 2007; Steinglass, Walsh, \& Stern, 2006). Additionally, semi-starvation likely contributes to anorexic clients' obsessive focus. Individuals in a state of semistarvation may fixate on food and develop symptoms that mimic obsessivecompulsive disorder (Goldner, Birmingham, \& Smye, 1997). Similarly, clients with $\mathrm{BN}$ tend to experience cognitive impairment in the form of increased impulsivity and risk taking (Fisher, Smith, \& Anderson, 2003; Peñas-Lledó, Vaz, Ramos, \& Waller, 2002; Rosval et al., 2006; Steiger, Lehoux, \& Gauvin, 1999) and individuals with $\mathrm{BN}$ are less inhibited in their responses, especially when experiencing negative emotions (Bruce, Koerner, Steiger, \& Young, 2002; Rosval et al., 2006). Furthermore, individuals with binge eating disorder may experience cognitive impairment, especially deficits related to problem-solving, cognitive flexibility, and working memory (Duchesne et al., 2010).

Individuals with these types of cognitive impairments and impulse control issues often need intensive outpatient or inpatient treatment in conjunction with medical and nutritional consultation. Counseling is vital for individuals with EDs, and individual therapies frequently include Cognitive Behavioral Therapy 
(CBT), Interpersonal Psychotherapy (IP), and Dialectical Behavior Therapy (DBT). Family and group therapies may also be useful. However, some researchers (Mehler et al., 2010) believe that counseling cannot be effective for cognitively impaired clients who are in states of self-starvation, and suggest that re-feeding treatment is more appropriate. Re-feeding involves gradually increasing in a client's consumption of food. It is often a risky process due to the possibility of heart failure, seizures, and blood and skeletal muscle dysfunction. When a client's weight is very low at the time of admission, re-feeding can be dangerous. The dangers associated with re-feeding may warrant inpatient treatment for individuals suffering from AN so that the process can be medically monitored (National Institute for Health and Clinical Excellence (NICE), 2004). Again, people with EDs are often unaware of their potentially life-threatening situation. Whereas they are not purposefully attempting to end their lives, AN sufferers have the highest mortality rate of all mental health disorders (APA, 2009; Sullivan, 2002). Individuals with this condition are often reluctant to enter treatment and may require hospitalization, often against their will, to prevent further life-threatening medical complications as impending medical crises are difficult to foresee in clients with EDs (APA, 2009; Goldner, et al., 1997).

\section{Ethical Principles}

In the helping professions, codes of ethics exist to provide standards of ethical conduct for practitioners and to provide a system of professional accountability that serves to protect the public. Underlying the codes of ethics are basic moral principles. Kitchener (1984) identified five moral principles that are generally viewed as the foundation for the ethical guidelines of the American Counseling Association's (ACA) Code of Ethics (2005). These principles of autonomy, nonmaleficence, beneficence, justice, and fidelity are considered to be of equal importance. Exceptions occur when one principle conflicts with another or is competing with a greater ethical duty (Herlihy \& Corey, 2006; Welfel, 2010). When fundamental principles are in conflict, counselors must seek a well -considered balance. When counselors consider mandating treatment for a client with a life-threatening ED, they must specifically consider the principles of autonomy, beneficence, and nonmaleficence in order to find a critical balance between them.

\section{Autonomy}

Autonomy is the ethical principle associated with an individual's right to independence and self-determination (Kitchener, 1984). Inherent in the concept of autonomy is the notion that clients are free to make self-directed choices without interference from others. To promote client autonomy, counselors cultivate independent decision-making and encourage client self-reliance by remaining open to values that are different from their own, by refraining from judgment, 
and by avoiding imposing goals on clients. Paternalism occurs when one individual attempts to determine the best interests of another person and may take place when counselors choose to make decisions on behalf of clients whom they believe have limited, intermittent, or no competence to make self-directed choices (Beauchamp \& Childress, 2001). When counselors exercise paternalism in order to uphold the principle of beneficence - to ensure the welfare of the client - they are infringing on the client's right to autonomy.

\section{Beneficence}

Beneficence is the ethical principle associated with the responsibility of counselors to do good in order to promote and safeguard the welfare of their clients (Kitchener, 1984). For counselors, this ethical responsibility requires that they contribute to the mental health, wellness, and growth of clients, engage in professional activities that benefit society as a whole, and work within the limits of their competency and scope of practice. Counselors are duty-bound to put forth their best effort to help clients even though their attempts may not always attain positive treatment outcomes. However, when specific treatments or interventions are attempted and prove to be unsuccessful, counselors must present clients with alternative options. The principle of beneficence requires a counselor to provide treatment that not only improves well-being, but also prevents harm.

\section{Nonmaleficence}

Nonmaleficence is the ethical principle associated with doing no harm (Kitchener, 1984). Not only must a counselor avoid intentionally hurting a client, he or she must also avoid engaging in actions that have a likelihood of causing harm. This principle is the basis for the ethical standards of competence to practice, informed consent, dual relationships, and public statements. Some ethicists (Beauchamp \& Childress, 1979) have noted that avoiding harm (including threats to autonomy and justice) necessitates a stronger ethical obligation than doing good. Following this logic, taking no action would be considered preferable to engaging in action that is likely to cause harm.

\section{Ethics and Eating Disorders}

A counselor must find a critical balance between autonomy, beneficence, and nonmaleficence in treating clients with severe EDs. When considering autonomy, a counselor might conclude that a competent client has the right to make decisions about his or her treatment and level of care. In addition, a counselor may assume that such a client has the freedom and responsibility to determine whether to seek treatment at all. Because the principle of autonomy underlies a client's right to make a decision about initiating treatment, one may surmise that a counselor's role is simply to provide a compassionate, supportive, and educational environment while offering neither encouragement nor dis- 
couragement about intensifying treatment. Similarly, some view the decision to recommend intensive treatment as a violation of the client's right to autonomy and as counterproductive to treatment (Dresser, 1984; Rathner, 1998). Some ethicists have argued that loss of autonomy due to coerced treatment can be detrimental to the therapeutic relationship (Griffiths \& Russell, 1998). In the case of a life-threatening condition such as AN, client autonomy would be upheld by withholding a recommendation regarding coerced treatment; however, this decision may then infringe on other ethical principles. For example, when considering nonmaleficence, one may infer that a counselor's inaction can harm the client through passive negligence; therefore, the counselor must take action to protect the client's welfare.

When considering the case from the perspective of beneficence, a counselor may argue that because EDs, particularly AN, are undeniably lethal when untreated, interventions such as involuntary hospitalization may be necessary (Griffiths \& Russell, 1998; Werth, Wright, Archambault, \& Bardash, 2003). Perhaps a counselor would reason that compulsory treatment would not only prevent harm, but also promote psychological well-being in clients with potentially lethal EDs. In the hypothetical case study presented below, we provide an example of the multiple ethical dilemmas counselors working with EDs may encounter.

\section{The Case of Lauren}

Lauren, a 20-year-old, Caucasian, female who is sophomore at a private university in the United States, presented to counseling at the urging of her parents and campus life personnel. Lauren had a history of concerns with her weight that became apparent at the age of 15 . Attempts at weight loss were coupled with frequent comments about feeling fat and the desire to lose weight. During the summer prior to her sophomore year of college, Lauren lost 25 pounds over the course of two months. When she came home during her next break, her parents noticed that Lauren's weight loss had progressed and they pleaded with her to get help.

After returning to school, Lauren fainted at the campus fitness center and was taken to the emergency room, where she was treated for dehydration, low blood sugar, and low blood pressure. She was told that her condition likely resulted from malnourishment. In addition to alerting Lauren's parents, campus personnel required Lauren to seek counseling before she could resume her classes. Lauren's parents contacted Carol, a licensed professional counselor, and provided her with reports from the hospital, which indicated that Lauren was 5'3, weighed 98 pounds, and had a body mass index (BMI) of $17.36 \mathrm{~kg} / \mathrm{m} 2$.

Lauren reluctantly met with Carol the following week and reported a willingness to attend counseling, if only to stay enrolled in school. Lauren signed 
a release-of-information for her parents, but indicated that the information could be released for billing purposes only. She did however list her parents as emergency contacts. During the session, Carol shared her concerns with Lauren about the medical information she had received in the hospital reports. Lauren denied having problems with food or eating and reported feeling perfectly healthy.

Over several sessions, Carol noticed Lauren's face becoming increasingly gaunt and she appeared tired and lethargic. Lauren continued to deny being underweight and expressed frustration with constantly being questioned about her weight. Carol recommended that Lauren have a follow up medical examination and see a nutritionist. Carol utilized psychoeducational interventions with Lauren and emphasized the dangers of her low weight and the potentially harmful impact of maintaining her current behavior. Lauren reluctantly agreed to see her primary care physician and authorized Carol and the physician to share information. The physician notified Carol that Lauren now weighed 89 pounds and that her BMI had decreased to $15.77 \mathrm{~kg} / \mathrm{m} 2$. The physician also reported that she had recommended inpatient treatment to Lauren to ensure her physical safety because she was in danger of severe electrolyte imbalance and cardiac arrest; Lauren told the doctor that she would consider additional treatment. During their next session, Carol asked Lauren if she was willing to engage in more intensive treatment. Lauren refused, saying that the doctor didn't know her very well and that she only intended to placate the physician by telling her she would consider additional treatment options.

\section{Ethical Decision-Making in the Case of Lauren}

In her work with Lauren, it is clear that Carol was faced with a significant ethical dilemma. She wanted to promote her client's autonomy, but questioned Lauren's cognitive capability to make responsible and healthy decisions for herself. In the following section, the aforementioned case will be used to illustrate the application of an ethical decision-making model. Although there are many appropriate and useful ethical decision-making models, Welfel (2010) designed a ten-step model for ethical decision-making that encourages consultation, education, and thoughtfulness which is thorough, clear, and highly applicable to the type of ethical decision-making faced by counselors on a routine basis. The ten steps of Welfel's model are: (a) develop ethical sensitivity; (b) clarify and consider facts, stakeholders, and the sociocultural context of the dilemma; (c) define central issues and available options; (d) refer to professional standards and relevant laws or regulations; (e) search out ethical scholarship; (f) apply ethical principles to the situation; (g) consult with supervisors and professional colleagues; (h) deliberate and decide; (i) implement the chosen action and document; and (j) reflect on the experience. In the following section, each of these ten steps will be described as they apply to Carol's dilemma. 


\section{Step One: Develop Ethical Sensitivity}

Attention to ethical decision making development should not only occur in the context of an ethically challenging situation, but should be developed intentionally over time. Carol's development of ethical sensitivity began when she studied both diagnosis and ethics during the course of her education. She completed an internship at a facility specializing in the treatment of individuals with EDs and attended professional conferences where she received additional training in ethics. Her experience and training were integral to her understanding of ethical questions involving autonomy, beneficence, and nonmalificence specific to Lauren's case.

\section{Step Two: Clarify and Consider Facts, Stakeholders, and the Sociocultural Context}

Clients with EDs may intentionally withhold facts about their weight, eating behavior, and exercise (APA, 2009). Counselors must utilize clinical skills to assess and discern important facts. In this case, Carol made herself aware of the key facts that impacted her eventual decision. She knew Lauren wanted to keep her parents uninvolved in the details of her condition. Carol determined the medical facts surrounding Lauren's weight and health. She was aware of Lauren's tendency to deny the severity of her condition and of her probable path toward physical decline. Due to her weight loss, refusal to eat, continued intense exercise, and physical danger, Carol identified the primary stakeholder in this case as Lauren herself. Lauren's parents also had a stake in her recovery, as they would likely be harmed by her continued deterioration. Carol was aware that ongoing counseling would be essential to Lauren's continued enrollment at the university and that punitive measures could be implemented if Lauren was not successful in her recovery. Additionally, Carol considered the myriad sociocultural implications on clients with EDs, such as the social pressure to be thin, which is often perpetuated by the media.

\section{Step Three: Define Central Issues and Available Options}

Counselors define the central problem by evaluating pertinent issues and assessing their likely impact on the client. The counselor brainstorms available options, remaining acutely aware of personal judgments and the impact of these beliefs on the decision-making process. Counselors may ask themselves whether, because of closely held attitudes, values, and biases, they are averse to any options in particular. In this case, Carol determined that the central issue was Lauren's life, which was likely in jeopardy due to her critically low weight. Carol identified a secondary issue involving the long-term health consequences of Lauren's current behavior. Carol brainstormed possible options, which included informing Lauren's parents of her dangerous condition, seeking involuntary hospitalization, or taking no action. Carol also thoughtfully considered her own 
values and how her desire to preserve life may come into conflict with Lauren's autonomy.

\section{Step Four: Refer to Professional Standards and Relevant Laws/ Regulations}

The ACA's Code of Ethics (2005) does not have a section that directly addresses specific mental health disorders like EDs, but instead provides a framework for promoting autonomy, beneficence, and nonmaleficence when working with clients. Carol found the following articles of the code to be relevant to her case: (a) A.1.a- the primary responsibility of counselors is to respect the dignity and promote the welfare of clients; (b) A.2.b.- clients have the right to... refuse any services or modality change and to be advised of the consequences of such refusal; (c) A.2.d.- when counseling... persons unable to give voluntary consent, counselors seek the assent of clients to services, and include them in decision-making as appropriate. Counselors recognize the need to balance the ethical rights of clients to make choices, their capacity to give consent or assent to receive services, and parental or familial legal rights and responsibilities to protect these clients and make decisions on their behalf; (d) A.4.a.-counselors act to avoid harming their clients... and to minimize or to remedy unavoidable or unanticipated harm; (e) A.4.b.- counselors are aware of their own values, attitudes, beliefs, and behaviors and avoid imposing values that are inconsistent with counseling goals; and (f) B.2.a.- the general requirement that counselors keep information confidential does not apply when disclosure is required to protect clients or identified others from serious and foreseeable harm...Counselors consult with other professionals when in doubt as to the validity of an exception.

\section{Step Five: Search out Ethics Scholarship}

In this case, Carol sought out scholarly books and articles about legal and ethical decision-making in cases of $\mathrm{AN}$ in which coerced treatment was deliberated. Carol found research investigating the risks and benefits of involuntary hospitalization and sought out position pieces written by ethicists about the treatment of EDs. She discovered that coerced treatment does not necessarily serve to advance the progress of clients with severe EDs, but rather merely serves to provide temporary medical stabilization (Rathner, 1998). She also found three studies that investigated the outcome of involuntary hospitalization for clients with severe EDs (Griffiths, Beumont, Russell, Touyz, \& Moore, 1997; Ramsay, Ward, Treasure, \& Russell, 1999; Watson, Bowers, \& Anderson, 2000). Russell (2001) summarized the results of these three studies and found that all of them indicated that clients who were hospitalized involuntarily experienced successful re-feeding on par with clients who were hospitalized voluntarily, although involuntary clients took longer to improve. Ramsay et al. (1999) found that, at approximately six years after admission, clients who had been involuntarily hospitalized had a higher mortality rate than those clients who were 
admitted voluntarily. The researchers speculated that the higher rate of mortality was attributable to a higher severity of illness upon hospitalization. Watson et al. (2000) reported that short term treatment outcomes were similar between clients who were involuntarily hospitalized and those who were voluntarily hospitalized. Carol was perplexed by these mixed results; it is important to note that while searching for relevant ethics literature, a counselor may not readily find an answer to his or her dilemma. This is particularly true with EDs because of the controversy surrounding the issues of compulsory treatment and autonomy for clients with cognitive impairment. However, with further research, Carol found that after reaching a stable condition, clients often acknowledge that they did in fact need treatment and express appreciation for the intervention (Anderson, Bowers, \& Evans, 1997; Goldner, Birmingham, \& Smye, 1997; Guarda et al., 2007).

\section{Step Six: Apply Ethical Principles to the Situation}

At this point in the decision-making process, a counselor would examine possible courses of action and determine their fit with fundamental ethical principles. The ethical problem for Carol was finding a balance between promoting good, doing no harm, and maintaining autonomy. Carol was familiar limitations to confidentiality in cases of imminent harm to self or others and deliberated whether Lauren's unhealthy weight constituted imminent harm to self. Because she believed that Lauren would benefit from inpatient treatment and knew that parental or university involvement would likely enforce that recommendation, Carol considered taking this action to promote Lauren's well-being. Carol understood that doing so would infringe on Lauren's autonomy, although she realized that Lauren may have been cognitively impaired to the extent that her decisionmaking abilities were compromised. Carol weighed the risk of harm to Lauren's autonomy and to their therapeutic relationship against the risk of harm to the client due to further medical decline and even death.

\section{Step Seven: Consult with a Supervisor and Respected Colleagues}

In this step, a counselor may seek consultation from colleagues, supervisors, treatment team members, and medical professionals in order to generate ideas, gain objective feedback, and garner emotional support. Because EDs directly impact clients' health and are potentially life-threatening, seeking medical consultation is vitally important. Counselors may also seek ethical consultation by contacting the ACA Ethics and Professional Standards Department (1800-347-6647, ext. 314; ethics@counseling.org).

Early in the course of counseling with Lauren, Carol sought consultation from a respected colleague who was well-versed in EDs and their medical implications. At a critical juncture, Carol pursued consultation with her colleague once again to consider her options. In addition, knowing that medical profes- 
sionals can help counselors evaluate the physical risk and aid in the difficult decision-making process, Carol sought consultation with a physician who specialized in treating EDs.

\section{Step Eight: Deliberate and Decide}

Once the facts have been gathered, the counselor independently deliberates and decides on a course of action. Often, in emergency ethical decisionmaking situations, a counselor proceeds through the previous seven steps rapidly, as he or she must act quickly in order to best serve the client. During this step, even in light of likely time constraints, it is important that the counselor carefully and thoughtfully consider the selected action regarding the fundamental ethical principles.

In the previous seven steps, Carol examined her values, reviewed the facts of the case, applied related laws and ethical principles, and sought consultation. She reviewed research that suggested that in most cases, involuntary hospitalization resulted in immediate physical safety, rather than clinically significant progress for an individual (Carney, Tait, Wakefield, Ingvarson, \& Touyz, 2005). Carol found herself agreeing with the assertion that involuntary hospitalization does not guarantee client improvement, nor does lack of treatment guarantee that a client will decline (Dresser, 1984; Rathner, 1998). However, Carol weighed her options carefully and decided that she would indeed inform Lauren's parents, her emergency contacts, with or without Lauren's consent. She determined that Lauren's rapid weight loss did constitute imminent danger and that Lauren's physical decline and continued self-harm required action on her part. She considered the alternative of taking no action and determined that the risks of allowing Lauren to proceed on her current trajectory outweighed the benefits of affording Lauren complete autonomy. Carol deliberated on the ways in which she could follow through with her decision while maintaining the most autonomy for her client.

\section{Step Nine: Implement the Chosen Action and Document}

Once the decision has been made, the counselor informs the appropriate people and implements the chosen action. If the counselor is currently working under supervision, the counselor will inform the supervisor of the decision before taking action. If the counselor decides to act against the client's will, such as enforcing treatment, the client may resist or feel betrayed by the counselor's decision. It is imperative that the counselor address a client's concerns and convey empathy even when implementing a decision that is directly against a client's wishes. In Lauren's case, Carol informed Lauren that she believed it was necessary to include her parents in the decision-making process regarding treatment. Carol expressed her fears for Lauren's life and conveyed that Lauren's safety was her primary concern. Lauren once again dismissed Carol's 
concerns and minimized her condition. She expressed fear that her parents would be angry and that inpatient treatment would interfere with her life. She expressed disbelief that her condition was severe enough to warrant hospitalization. Carol listened empathically to and validated her concerns. She discussed the possible consequences of not informing her parents or pursuing inpatient treatment, including a possible continued decline in health and potential death. Once Lauren realized that Carol was informing her parents with or without her consent, she agreed to be a part of the process and do so on her own terms. Carol involved Lauren in decision-making as much as possible, including giving her the choice of calling her parents herself, helping her to look through various brochures about available treatment programs, and encouraging her to think about, among the various options, which would be the best fit for her. Carol made every effort to respectfully consider Lauren's feelings during the process. Together, Carol and Lauren decided to inform Lauren's parents by phone that day. Lauren selected a fitting treatment program and agreed to go once arrangements were made. Her parents supported her decision. In her case notes, Carol formally documented her consultation experience, research, decision-making process, and the actions she implemented.

\section{Step Ten: Reflect on the Experience}

After the decision has been made, implemented, and documented, the counselor then reflects on the process. In this case, Carol struggled with the difficult dilemma of balancing autonomy with beneficence and nonmaleficence. Reflecting on the first nine steps, Carol reviewed her actions, assessed the quality of her actions in each of the steps of the ethical decision-making model, discussed the process and outcome with her professional colleagues, and began keeping a journal about her experiences. The process of ethical decisionmaking in Lauren's case was difficult and stressful for Carol as she feared damaging the counseling relationship and, thus, harming her client. With much reflection, she came to the conclusion that the risk of imminent harm to Lauren necessitated action and that damage to their relationship was a necessary risk. By consulting with colleagues, Carol sought support and learned of others' similar experiences, which she found helpful. While Lauren was in treatment, Carol checked in with her progress and was relieved to learn that Lauren appreciated her decision to compel her to get help and that these actions translated into caring and concern. Although Carol did not do so, counselors may wish to seek additional formal supervision and/or attend personal counseling.

Whereas Carol ranked beneficence and nonmaleficence above client autonomy in her decision-making process in this case, other counselor may have drawn very different, potentially appropriate conclusions after implementing the same decision-making process. Because each client case is unique, conclusions to decision-making processes will likely also be unique. Once 
again, there is no one right answer to any given ethical dilemma, including dilemmas involving ED cases.

\section{Conclusion}

Providing counseling to clients with eating disorders can be intense, complex, and ethically challenging work, as is evidenced by the case of Lauren. This case serves to illustrate that ethical decisions, even when carried out by experienced counselors, require careful deliberation over multiple steps. It should be noted that counselors who do not have training or experience in treating eating disorders may best serve clients by providing referrals in a caring and empathetic manner. In order to best balance ethical principles, counselors facing ethical dilemmas with any client, including those with EDs, will likely benefit from the use of an ethical decision-making model such as Welfel's (2010) model, which emphasizes training in ethics, utilization of consultation and available research, and reflection after ethical decisions are made.

\section{References}

American Counseling Association. (2005). Code of ethics and standards of practice. Alexandria, VA: Author.

American Psychiatric Association. (2013). Diagnostic and statistical manual of mental disorders (5th ed.). Arlington, VA: American Psychiatric Publishing.

American Psychological Association. (2009). Treatment of patients with eating disorders (3rd ed.). Retrieved from http://psycho.silverchair.com/ pracGuide/pracguideChapToc_12.aspx. doi: 10.1176/ appi.books.9780890423363.138660

Andersen, A. E., Bowers, W., \& Evans, K. (1997). Inpatient treatment of anorexia nervosa. In D.M. Garner \& P. E. Garfinkel (Eds.), Handbook of treatment for eating disorders (2nd ed., pp. 327-353). New York, NY: Guilford.

Apter, A., Gothelf, D., Orbach, I., Weizman, R., Ratzoni, G., \& Har-Even, D. (1995). Correlation of suicidal and violent behavior in different diagnostic categories in hospitalized adolescent patients. Journal of the American Academy of Child Adolescent Psychiatry, 34, 912-918.

Beauchamp, T. L., \& Childress, J. F. (1979). Principles of biomedical ethics. Oxford, UK: Oxford University Press.

Boeka, A. C., \& Lokken, K. L. (2006). The lowa Gambling Task as a measure of decision making in women with bulimia nervosa. Foumal of the Internationat Neuropsychotogicat Society, 12, 74-745.

Brand, M., Frank-Sievert, C., Jacoby, G. E., Markowitsch, H. J., \& TuschenCaffier, B. (2007). Neuropsychoiogical correlates of decision-making in patients with bulimia nervosa. Neuropsychology, 21, 742-750.

Bruce, K. R., Koerner, N. M., Steiger, H., \& Young, S. N. (2002). Laxative misuse and behavioural disinhibition in bulimia nervosa. International Journal of Eating Disorders, 33, 92-97. 
Bulik, C. M., Sullivan, P. F., \& Joyce, P. R. (1999). Temperament, character and suicide attempts in anorexia nervosa, bulimia nervosa and major depression. Acta Psychiatrica Scandinavica, 100, 27-32.

Carney, T., Wakefield, A., Tait, D., \& Touyz, S. (2006). Reflections on coercion in the treatment of severe anorexia nervosa. Israel Journal of Psychiatry and Related Sciences, 43(3), 159-165.

Cavedini, P., Bassi, T., Ubbiali, A., Casolari, A., Giordani, S., \& Zorzi, C. (2004). Neuropsychological investigation of decision-making in anorexia nervosa. Psychiatry Research, 127, 259-266.

Cavedini, P., Zorzi, C., Bassi, T., Gorini, A., Baraldi, C., \& Ubbiali, A. (2006).

Decision-making functioning as a predictor of treatment outcome in anorexia nervosa. Psychiatry Research, 145, 179-187.

Corcos, M., Taieb, O., Benoit-Lamy, S., Paterniti, S., Jeammet, P., \& Flament, M. F. (2002). Suicide attempts in women with bulimia nervosa: Frequency and characteristics. Acta Psychiatrica Scandinavica, 106, 381386.

Crow, S. J., Peterson, C. B., Swanson, S. A., Raymond, N. C., Specker, S., Eckert, E. D., \& Mitchell J. E. (2009). Increased mortality in bulimia nervosa and other eating disorders. American Journal of Psychiatry, 166, $1342-1346$.

Dresser, R. (1984). Legal and policy considerations in treatment of anorexia nervosa patients. International Journal of Eating Disorders, 3(4), 43-51. Duchesne, M., Mattos, P., Appolinário, J., de Freitas, S., Coutinho, G., Santos, C., \& Coutinho, W. (2010). Assessment of executive functions in obese individuals with binge eating disorder. Revista Brasileira De Psiquiatria, 32(4), 381-388.

Eisher, S., Smith, G. T., \& Anderson, K. G. (2003). Clarifying the role of impulsivity in bulimia nervosa. International Journal of Eating Disorders, 33, 406-411.

Favaro A., \& Santonastaso P. (1997). Suicidality in eating disorders: Clinical and psychological correlates. Acta Psychiatrica Scandinavica, 95, 508514.

Goldner, E. M., Birmingham, C. L., \& Smye, V. (1997). Addressing treatment refusal in anorexia nervosa: Clinical, ethical, and legal considerations. In D.M. Garner, and P.E. Garfinkel (Eds.), Handbook of treatment for eating disorders ( $2^{\text {nd }}$ ed., pp. 450-461). New York, NY: Guilford Press.

Griffiths, R. A., Beumont, P. J. V., Russell, J., Touyz, S. W., \& Moore, G. (1997). The use of guardianship legislation for anorexia nervosa: A report of 15 cases. Australian and New Zealand Journal of Psychiatry, 31, 525-531.

Griffiths, R., \& Russell, J. (1998). Compulsory treatment of anorexia nervosa patients. In W. Vandereycken, P. V. Beumont, W. Vandereycken, P. V. Beumont (Eds.), Treating eating disorders: Ethical, legal and personal issues (pp. 127-150). New York, NY: New York University Press.

Guarda, A. S., Pinto, A., Coughlin, J. W., Hussain, S., Haug, N. A., \& Heinberg, L. J. (2007). Perceived coercion and change in perceived need for admission in patients hospitalized for eating disorders. The American Journal of Psychiatry, 164, 108-114.

Herlihy, B., \& Corey, G. (2006). ACA ethical standards casebook (6th ed.). Alexandria, VA: American Counseling Association. 
Kitchener, K. S. (1984). Intuition, critical evaluation and ethical principles: The foundation for ethical decisions in counseling psychology. The Counseling Psychologist, 12, 43-55.

Mehler, P., Winkelman, A., Andersen, D., \& Gaudiani, J. (2010). Nutritional rehabilitation: Practical guidelines for refeeding the anorectic patient. Journal of Nutrition and Metabolism. Available from MEDLINE. Retrieved from http://web.ebscohost.com.

National Collaborating Centre for Mental Health. (2004). Eating disorders: Core interventions in the treatment and management of anorexia nervosa, bulimia nervosa, and related eating disorders. London, UK: The British Psychological Society and Gaskell.

Peñas-Lledó, E., Vaz, ¥. J., Ramos, M. L., \& Waller, G. (2002). Impulsive behaviours in bulimic patients: Relation to general psychopathology. International Journal of Eating Disorders, 32, 98-102.

Pompili, M., Manccinelli, I., Girardi, P., Ruberto, A., \& Tatarelli, R. (2004). Suicide in anorexia nervosa: A meta-analysis. International Journal of Eating Disorders, 36, 99-103. doi:10.1002/eat.20011

Preti, A. A., Rocchi, M. L., Sisti, D. D., Camboni, M. V., \& Miotto, P. P. (2011). A comprehensive meta-analysis of the risk of suicide in eating disorders. Acta Psychiatrica Scandinavica, 124(1), 6-17. doi:10.1111/j.16000447.2010.01641.x

Pryor, T., Wiederman M. W., \& McGilley. B. (1995). Clinical correlates of anorexia nervosa subtypes. International Journal of Eating Disorders, 19, 371-379.

Ramsay, R., Ward, A., Treasure, J., \& Russell, G. (1999). Compulsory treatment in anorexia nervosa. British Journal of Psychiatry, 175, 147-153.

Rathner, G. (1998). A plea against compulsory treatment of anorexia nervosa patients. In W. Vandereycken, P. V. Beumont, W. Vandereycken, P. V. Beumont (Eds.). Treating eating disorders: Ethical, legal and personal issues (pp. 179-215). New York, NY: New York University Press.

Roberts, M. E., Tchanturia, K., Stahl, D., Southgate, L., \& Treasure, J. (2007). A systematic review and meta-analysis of set-shifting ability in eating disorders. Psychological Medicine, 37, 1075-1084.

Rosval, L., Steiger, H., Bruce, K. R., Israel, M., Richardson, J., \& Aubut, M. (2006). Impulsivity in women with eating disorders: Problem of response inhibition, planning, or attention? International Journal of Eating Disorders, 39, 590-593.

Russell, G. F. M. (2001). Involuntary treatment in anorexia nervosa. Psychiatric Clinics of North America, 24, 337-349.

Schoen, E. V., Lee, S., Skow, C., Greenberg, S. T., Bell, A. S., Wiese, J. A., \& Martens, J. K. (2012). A retrospective look at the internal help-seeking process in young women with eating disorders. Eating Disorders, 20, 14-30. doi: 10.1080/10640266.2012.635560

Steiger, H,, Lehoux, P. M., \& Gauvin, L. (1999). Impulsivity, dietary control and the urge to binge in bulimic syndromes. International Journal of Eating Disorders, 26, 261-274.

Steinglass, J. E., Walsh, B. T., \& Stern, Y. (2006). Set shifting deficit in anorexia nervosa. Journal of the international Neuropsychological Society, 12, 431-435. 
Stice, E., Marti, C., \& Rohde, P. (2013). Prevalence, incidence, impairment, and course of the proposed DSM-5 eating disorder diagnoses in an 8-year prospective community study of young women. Journal of Abnormal Psychology, 122(2), 445-457. doi:10.1037/a0030679

Sullivan, P. F. (2002). Course and outcome of anorexia and bulimia nervosa. In C. G. Fairburn \& K. D. Brownell (Eds.), Eating disorders and obesity (2nd ed., pp. 226-232). New York, NY: Guilford Press.

Sullivan, P. F. (1995). Mortality in anorexia nervosa. The American Journal of Psychiatry, 152, 1073-1074.

Tchanturia, K., Liao, P., Uher, R., Lawrence, N., Treasure, J., \& Campbell, I. C. (2007). An investigation of decision making in anorexia nervosa using the lowa Gambling Task and skin conductance measurements. Journal of the International Neuropsychological Society, 13, 1-7.

Watson, T. L., Bowers, W. A., \& Andersen, A. E. (2000). Involuntary treatment of eating disorders. American Journal of Psychiatry, 157, 1806-1810.

Welfel, E. R. (2010). Ethics in counseling and psychotherapy: Standards, research, and emerging issues ( $4^{\text {th }}$ ed.). Belmont, CA: Brooks/Cole.

Werth, J. R., Wright, K. S., Archambault, R. J., \& Bardash, R. (2003). When does the 'duty to protect' apply with a client who has anorexia nervosa? The Counseling Psychologist, 31, 427-450. 